\title{
Harnessing the Secretome of Mesenchymal Stromal Cells for Traumatic Spinal Cord Injury: Multicell Comparison and Assessment of In Vivo Efficacy
}

\author{
Reaz Vawda, ${ }^{1, *}$ Anna Badner,, ${ }^{1,, *}$ James Hong, ${ }^{1,2}$ Mirriam Mikhail, ${ }^{1}$ Rachel Dragas,,2,\# \\ Kristiana Xhima, ${ }^{1, \#}$ Alejandro Jose, ${ }^{1}$ and Michael G. Fehlings ${ }^{1-3}$
}

Cell therapy offers significant promise for traumatic spinal cord injury (SCI), which despite many medical advances, has limited treatment strategies. Able to address the multifactorial and dynamic pathophysiology of SCI, cells present various advantages over standard pharmacological approaches. However, the use of live cells is also severely hampered by logistical and practical considerations. These include specialized equipment and expertise, standardization of cell stocks, sustained cell viability post-thawing, and cryopreservation-induced delayed-onset cell death. For this reason, we suggest a novel and clinically translatable alternative to live-cell systemic infusion, which retains the efficacy of the latter while overcoming many of its limitations. This strategy involves the administration of concentrated cell secretome and exploits the trophic mechanism by which stromal cells function. In this study, we compare the efficacy of intravenously delivered concentrated conditioned media (CM) from human umbilical cord matrix cells (HUCMCs), bone marrow mesenchymal stromal cells, as well as newborn and adult fibroblasts in a rat model of moderately severe cervical clip compression/contusion injury $(\mathrm{C} 7--\mathrm{T} 1,35 \mathrm{~g})$. This is further paired with a thorough profile of the CM cytokines, chemokines, and angiogenic factors. The HUCMC-derived CM was most effective at limiting acute $(48 \mathrm{~h}$ post-SCI) vascular pathology, specifically lesion volume, and functional vascularity. Principle component analysis (PCA), hierarchical clustering, and interaction analysis of proteins highly expressed in the HUCMC secretome suggest involvement of the MAPK/ERK, JAK/STAT, and immune cell migratory pathways. This "secretotherapeutic" strategy represents a novel and minimally invasive method to target multiple organ systems and several pathologies shortly after traumatic SCI.

Keywords: mesenchymal stromal cells, secretome, conditioned media, spinal cord injury, intravenous

\section{Introduction}

$\mathrm{S}$ PINAL CORD INJURY (SCI) affects 1.275 million individuals in the United States alone, with an annual incidence of 12,000 (www.christopherreeve.org). SCI-induced vascular disruption (VD) is an immediate consequence of SCI and is a trigger for secondary pathology [1]. For this reason, targeting early damage may reduce tissue loss as well as functional impairment, improving overall recovery. Cell therapy, especially mesenchymal stromal cells (MSCs), is a promising modality to address the multifactorial and dynamic secondary pathophysiology $[2,3]$.
MSCs are currently being tested in clinical trials for treating various central nervous system (CNS) degenerative as well as traumatic conditions, including SCI [4]. Importantly, MSCs also have pericytic attributes [5-11] that may effectively target VD. However, the acute treatment of SCI with live cells is severely hampered by several considerations. These include the need for skilled expertise and specialized equipment for cell manipulation, sustained cell viability post-thawing, cryopreservation-induced delayedonset cell death (CIDOCD) [12,13], standardization of cell stocks and time to cell administration after harvest. There is also the risk of pulmonary embolism post-cell infusion [14,15] even

\footnotetext{
${ }^{1}$ Department of Genetics and Development, Krembil Research Institute, University Health Network, Toronto, Canada.

${ }^{2}$ Institute of Medical Science, School of Medicine, University of Toronto, Toronto, Canada.

${ }^{3}$ Spinal Program, Toronto Western Hospital, University Health Network, Toronto, Canada.

*These co-first authors contributed equally to this work.

\#These authors contributed equally to this work.
}

(C) Reaz Vawda et al. 2020; Published by Mary Ann Liebert, Inc. This Open Access article is distributed under the terms of the Creative Commons Attribution Noncommercial License (http://creativecommons.org/licenses/by-nc/4.0/) which permits any noncommercial use, distribution, and reproduction in any medium, provided the original author(s) and the source are cited. 
though the safety of such an approach has been verified through meta-analysis [16], immune rejection [14], increased patient vulnerability, and severely compromised autonomic function. Despite improvements in cryopreservation techniques and reagents [17-26], current cell cryopreservation technologies are likely the bottleneck of cell therapy and CIDOCD is likely a factor in the challenges to translate cellular therapies to the clinic. Freeze-thawed MSCs have also been shown to have impaired immunomodulatory, blood regulatory, and therapeutic properties compared to freshly harvested cells from continuous cultures $[27,28]$. Finally, a limited understanding of the specific biology, molecular targets, and functional capacity of MSCs hinders any further exploitation of their therapeutic capabilities and impedes full-scale clinical deployment.

With these limitations in mind, we have developed a novel and clinically translatable alternative to live cell systemic infusion, which retains the efficacy of the latter while overcoming many of its limitations. Our strategy involves the administration of concentrated cell secretome and aims to exploit the trophic mechanism by which MSCs are reported to function after CNS transplantation or systemic infusion [29-32]. Further, cell secretome comprises growth factors, cytokines, chemokines, immunomodulatory molecules, and, more recently identified, extracellular vesicles $[33,34]$. Yet, as cell paracrine action is significantly influenced by microenvironment, cell source, and passage number [35], characterization as well as comparison studies will be instrumental for successful application of secretome for therapeutic purposes. Therefore, as we have demonstrated success with human umbilical cord matrix cells (HUCMCs) [36-38], we aimed to compare their concentrated conditioned media $(\mathrm{CM})$ with their adult counterparts from bone marrow mesenchymal stromal cells (BMSCs). Notably, HUCMCs are also more attractive candidates than other adult or fetal MSCs for a variety of reasons, including their greater proliferative potential, noninvasive and ethical derivation, and sourcing from term births $[39,40]$.

In this study, we present evidence that early $(7 \mathrm{~min}$ postSCI) intravenous delivery of HUCMC secretome has a greater effect on SCI secondary pathology than that of BMSCs, as well as adult and newborn (NB) human foreskin fibroblasts. Furthermore, using principle component analysis (PCA) and hierarchical clustering and interaction analysis of the cell secretome, we also demonstrate that HUCMC-CM contains proteins that are involved in the MAPK/ERK, JAK/ STAT, and immune cell migratory pathways, highlighting a novel target for neuroprotection. Therefore, taken together, this study not only provides a thorough comparison of various human cell-derived secretomes, but also shows the clinical feasibility of human cell-derived secretomes for various traumatic and neurodegenerative conditions [4146]. As this approach has significant advantages over live cell-based therapeutic approaches, it has important translational implications.

\section{Materials and Methods}

All experiments involving animal use were approved by the University Health Network Animal Care Committee (Animal Use Protocol No. 979) and experiments were carried out in strict accordance with approved protocols.

\section{HUCMC isolation}

A $3-5 \mathrm{~cm}$ segment of umbilical cord was collected from consenting mothers' postpartum in Chelsea and Westminster Hospital (London, United Kingdom; ethics code RREC 2758; R\&D reference 02TE002), and dissected in sterile Hank's Buffered Saline Solution (HBSS, Gibco) containing $1 \%$ gentamycin and 1\% Fungizone. The vein and arteries were carefully removed. Fragments of Wharton's jelly (umbilical cord matrix) were digested in collagenase I and II $(1 \mathrm{mg} / \mathrm{mL}, \mathrm{Gibco})$ for $2 \mathrm{~h}$ at $37^{\circ} \mathrm{C}$ before centrifuging at $2,000 \mathrm{rpm}$ for $10 \mathrm{~min}$. Cells were then seeded into uncoated culture flasks (Greiner) in Dulbecco's Modified Eagle Medium/F12 (Gibco) or Alpha-MEM containing 10\% batchtested nonheat inactivated fetal bovine serum (FBS; Wisent), $1 \%$ sodium pyruvate, $1 \%$ GlutaMAX, $0.1 \%$ gentamycin, and $0.1 \%$ Fungizone (Sigma-Aldrich; complete medium). After 2-5 days, nonadherent cells were removed, and the remaining cells were grown to $80 \%-90 \%$ confluence before passaging.

Other cell types used in the study include passagematched commercially obtained adult human BMSCs (PT2501; Lonza), as well as NB foreskin fibroblasts (ATCC, PCS-201-010) and adult fibroblasts (ATCC, PCS-201-012). Importantly, all cell cultures were regularly checked for mycoplasma (MycoAlert ${ }^{\mathrm{TM}}$ Mycoplasma Detection Kit, LT07-218; Lonza).

\section{Generation of concentrated CM}

For in vivo studies, all cells (passage-matched; passage 6) were cultured in T75 tissue culture flasks with Alpha-MEM $+10 \%$ FBS before serum withdrawal to $80 \%$ confluence. Before the addition of serum-free Alpha-MEM, the cells were washed three times with sterile HBSS (Gibco). CM was generated by collection of 1-week serum-free Alpha-MEM (from T75 tissue culture flasks with cells at $80 \%$ confluence). CM from different flasks were harvested and pooled. Subsequently, CM was concentrated using Pierce ultracentrifuge concentrators $(>9 \mathrm{kDa})$ by centrifugation at $4,000 \mathrm{~g}$ for 15 min. The mean protein concentration of concentrated CM was $1.2-1.7 \mathrm{mg} / \mathrm{mL}$ and samples were stored at $-80^{\circ} \mathrm{C}$.

\section{SCI model and CM infusion}

Careful consideration was given to approved standards of reporting for all procedures and data described (Animals in Research: Reporting in Vivo Experiments, ARRIVE and Minimum Information about a Spinal Cord Injury Experiment, MIASCI) [47-50]. Female Wistar rats (250-300 g, 12 weeks old) received a C7-T1 $35 \mathrm{~g}$ clip compression SCI for 1 min under isoflurane anesthesia $\left(1: 1\right.$ mixture of $\left.\mathrm{O}_{2} / \mathrm{NO}_{2}\right)$. For all acute studies ( $48 \mathrm{~h}$ post-SCI), a volume of $1 \mathrm{~mL}$ of concentrated CM (pooled from several dishes) was systemically infused via the tail vein $7 \mathrm{~min}$ post-SCI. For all long-term studies (10 weeks post-SCI), in addition to the initial treatment at $7 \mathrm{~min}$ post-SCI, the animals also received repeated $1 \mathrm{~mL}$ infusions at $1,2,3,7,14,21$, and 28 days. The animals were randomly assigned to a treatment group and given a coded designation until data acquisition and processing was complete. Specialized postoperative husbandry protocols were followed by qualified and experienced personnel (also blinded to treatment conditions) to maximize animal welfare. These included corn cob $\left(11^{\prime \prime}\right)$ 
and Isopad bedding, Clavamox-supplemented drinking water, and Bacon Softies diet (starting immediately post-op). Animals were caged singly postoperatively with Nylabone and kept on a 12-h light/dark cycle at all times. Manual bladder squeezing (three times a day), cyclosporine (Sandimmune) injections $(10 \mathrm{mg} / \mathrm{kg}$ s.c. once daily), and $\mathrm{Bu}-$ prenorphine injections $(0.05 \mathrm{mg} / \mathrm{kg}$ s.c. twice daily) were performed at regular times.

\section{In vivo very high-resolution ultrasound imaging for three-dimensional lesion/cavity volume assessment}

The injured spinal cord was imaged by in vivo very high resolution ultrasound imaging (VHRUS) as previously described [51,52] using a $44 \mathrm{MHz}$ probe (Vevo 770; VisualSonics). Three-dimensional (3D) VHRUS acquisitions were made in B-mode and Power Doppler mode. The $3 \mathrm{D}$ files were analyzed with Image ${ }^{\circledR}$ software as previously described [51,52] with minor modifications. The bright pixels (defined as lesional tissue) were delineated by two independent blinded observers within a 15 sagittal image serial stack $(102 \mu \mathrm{m}$ distance between sagittal images). Volumetric renderings of 3D lesional volume and cavity representations of the raw ultrasound images were generated with the TrakEM2 ImageJ plugin at $48 \mathrm{~h}$ and 10 weeks post-SCI, respectively.

\section{VHRUS 3D power Doppler analysis for spinal cord vascularity}

With in vivo Power Doppler ultrasound imaging, it is possible to detect the active large vessel blood flow and therefore spinal cord vascularity [51]. Although contrastenhanced ultrasonography is most commonly applied to quantify in vivo spinal cord perfusion and flow, power Doppler imaging has been shown to correlate with immunofluorescence measurements of blood vessel density [51]. We have adapted this approach to quantify the 3D spinal cord vascularization following injury and secretome treatments as previously reported $[36,53]$. In short, the percent area of Doppler signal for each sagittal image slice was summed, generating a robust measure of functional vascularity at $48 \mathrm{~h}$ and 10 weeks post-SCI.

\section{Evans blue assay for vascular permeability (48 $\mathrm{h}$ post-SCl)}

Wistar rats were infused with $1 \mathrm{~mL} 2 \%$ Evans blue (EB) dye in phosphate-buffered saline (PBS; without $\mathrm{Ca}^{2+}$ and $\mathrm{Mg}^{2+}$ ) $30 \mathrm{~min}$ before sacrificial perfusion with $250 \mathrm{~mL}$ chilled PBS. Snap-frozen $5 \mathrm{~mm}$-segment homogenates of lesional spinal cord tissue were each divided into three equal portions for spectrophotometric quantification of EB dye, the myeloperoxidase (MPO) activity assay, and Drabkin's assay. Therefore, a one-third portion of homogenized $5 \mathrm{~mm}$ lesion spinal cord tissue was dissolved in $500 \mu \mathrm{L}$ dimethylformamide (DMF), incubated at $50^{\circ} \mathrm{C}$ for $24 \mathrm{~h}$, and centrifuged at $13,000 \mathrm{rpm}$ for $15 \mathrm{~min}$. The supernatant was collected and $150 \mu \mathrm{L}$ was aliquoted into a 96-well flat bottom glass plate (Zeisser). Colorimetric measurements were performed using the Perkin Elmer Victor2TM 1420 spectrophotometer (Wallac 1420 Victor2TM; Perkin Elmer,
Waltham, MA) at $620 \mathrm{~nm}$. Samples were normalized to tissue weight (g) and EB concentration was calculated based on a standard curve in DMF, as previously described [54].

\section{Drabkin's assay for parenchymal hemorrhage (48 $\mathrm{h}$ post-SCl)}

Parenchymal hemorrhage was assessed via a modified version of the Drabkin's assay manufacturer protocol (D5941; Sigma). The sample was sonicated in $100 \mu \mathrm{L}$ deionized distilled $\mathrm{H}_{2} \mathrm{O}$ and subsequently centrifuged at $13,000 \mathrm{rpm}$ for $15 \mathrm{~min}$. The supernatant was collected and added to complete Drabkin's Reagent (Drabkin's Reagent powder in $1,000 \mathrm{~mL}$ of distilled $\mathrm{H}_{2} \mathrm{O}$ and $0.5 \mathrm{~mL}$ of $30 \%$ Brij 35 Solution) and allowed to stand for $15 \mathrm{~min}$ for the reaction to take place (hemoglobin to cyanomethemoglobin). Colorimetric measurements were performed using the Perkin Elmer Victor2TM spectrophotometer (Wallac 1420 Victor2TM; Perkin Elmer) at $540 \mathrm{~nm}$, normalized to tissue weight (in grams), and calculated based on a linear bovine blood hemoglobin (H2500; Sigma) standard curve.

\section{MPO activity assay for neutrophil infiltration (48 h post-SCl)}

MPO activity, a measure of neutrophil infiltration and inflammation post-SCI, was quantified using a kit from Enzo Life Sciences as per the manufacturer's instructions (ADI907-029) with minor modifications. In short, the samples were sonicated for $30 \mathrm{~s}$ in $1 \times \mathrm{MPO}$ buffer with $0.5 \%$ detergent hexadecyltrimethylammonium (HTA-Br; w/v, H9151; Sigma-Aldrich) and $10 \mathrm{mM}$ N-Ethylmaleimide (E3876; Sigma-Aldrich). Two freeze/thaws were then performed and the samples were subsequently centrifuged at $12,000 \mathrm{~g}$ for $20 \mathrm{~min}$ at $4^{\circ} \mathrm{C}$. Fifty microliters of sample supernatant and $50 \mu \mathrm{L}$ of the reaction cocktail was added and incubated for $60 \mathrm{~min}$. Fluorescence was measured on the Perkin Elmer Victor2TM 1420 spectrophotometer (Wallac 1420 Victor2TM; Perkin Elmer) at an excitation wavelength of $530 \mathrm{~nm}$ and emission wavelength of $590 \mathrm{~nm}$. MPO activity was determined from the measured relative fluorescence intensity of an MPO enzyme standard curve. Results were expressed relative to tissue mass (in grams).

\section{Proteome profiler arrays}

Vascular, trophic, and inflammatory factors in cell secretomes were probed using R\&D enzyme-linked immunosorbent assay (ELISA) Proteome Profiler arrays (ARY007, ARY017, and ARY005). They were used as per the manufacturer's instructions with minor modifications, specifically IRDye 800CW Streptavidin (LI-COR, 926-32230; www.RnDSystems .com/go/LICORProtocol) secondary was used at a 1:2,000 dilution for $30 \mathrm{~min}$ at room temperature to improve the sensitivity of detection. ELISA membranes were scanned on an Odyssey Imager (LICOR) using standardized acquisition parameters. Fluorescence intensity values for each array membrane are normalized to its own negative control spots, and ultimately represented as fold-differences relative to the HUCMC secretome. Each value is the mean of two spots on the ELISA membrane. The protein array values were validated through three replicates. However, as the concentrated CM was pooled from multiple flasks to obtain enough for characterization as 
well as in vivo animal studies, these were not biological replicates. Therefore, although HUCMCs secreted a greater variety and quantity of concentrations of cytokines, chemokines, and angiogenic proteins, there is no statistical comparison.

\section{Heat map and cluster analysis of arrays}

Mean gray values obtained from proteome profiling were imported into gConvert, a part of the gProfiler [55] suite of tools for conversion into standardized gene symbols. Datasets from each array analysis were imported into ClustVis [56] and subjected to unit variance scaling to normalize the expression of each protein. PCA was then completed using the singular value decomposition method and unsupervised hierarchical clustering was performed using correlation as distance and average linkage method for both the clustering of the rows (proteins) and columns (cell types). Cluster numbers were manually annotated by setting dendrogram cutoffs that best describe the type of clusters.

\section{Protein-protein interaction analysis}

Gene symbols were converted to protein IDs in STRING [57], and proteins that were highly expressed in HUCMC CM were imported (clusters \#3, \#2, and \#4 from the angiogenesis, chemokine, and cytokine arrays, respectively). Network edges were set to show the number of independent types of evidence for the interaction, active interaction sources were set to exclude text mining, but include experimental, database, coexpression, and homology-derived interactions. The minimum required interaction score was set to that of the highest confidence $(>0.9)$. Functional enrichment of these proteins and their proven interaction partners were done using the gene ontology and Kyoto Encyclopedia of Genes and Genomes databases, significant enrichments $(P$-adjusted $<0.05)$ were highlighted.

\section{Long-term (10 weeks post-SCl) neurobehavioral assessment}

Considering HUCMC CM had the most promising effects in acute studies ( $48 \mathrm{~h}$ post-SCI), long-term (10 weeks postSCI) assessment involved comparison between a vehicle (media only) control and HUCMC CM. All neurobehavioral assessments were performed weekly for 10 weeks after SCI by examiners blinded to the experimental group. Forelimb function was assessed with a grip strength meter (SDI Grip Strength System, model DFM-10; San Diego Instruments, San Diego, CA; www.sandiegoinstruments.com), as previously described [58]. Whole-body limb function and trunk stability was evaluated with the inclined plane test, where animals were placed on a horizontal plane, and the incline angle was incrementally raised until they were no longer able to maintain their position. Hindlimb locomotion was assessed using the 22-point (0-21) Basso, Beattie, and Bresnahan (BBB) Locomotor Rating Scale, as previously described [59]. The animals were also weighed weekly.

\section{Long-term (10 weeks post-SCI) spinal cord immunohistochemistry}

Five $\mathrm{mm}$ spinal cord segments $(2.5 \mathrm{~mm}$ rostral and $2.5 \mathrm{~mm}$ caudal from the epicenter) were isolated from rats intracardially perfused with $250 \mathrm{~mL}$ chilled PBS (without Calcium and Magnesium) followed by $50 \mathrm{~mL}$ of chilled $4 \%$ paraformaldehyde (PFA) and then postfixed in $4 \%$ PFA overnight at $4^{\circ} \mathrm{C}$ before transfer to $30 \%$ sucrose (at $4^{\circ} \mathrm{C}$ ) and stored in optimal cutting temperature compound (OCT) (at $4^{\circ} \mathrm{C}$ for $1-2$ days then $-20^{\circ} \mathrm{C}$ ). The $5 \mathrm{~mm}$ tissue segment was subsequently embedded in fresh OCT and dorso-ventral longitudinal cryosectioning $(30 \mu \mathrm{m}$ thick cross sections) took place. The delay between spinal cord isolation and cryosectioning was kept to a minimum. Before staining, slides were baked for $15 \mathrm{~min}$ at $55^{\circ} \mathrm{C}$ to improve cryosection adherence to the slides. After blocking in PBS (without Calcium and Magnesium) $+2 \%$ FBS $+0.3 \%$ Triton $\mathrm{X}$ for $1 \mathrm{~h}$ at room temperature, primary antibodies diluted in the same diluent solution were applied overnight at $4{ }^{\circ} \mathrm{C}$. Myelination was quantified using FluoroMyelin (F34651; 1:100; Molecular Probes), gliosis using anti-GFAP (AB5541, 1:200; Millipore), and vascularity with DyLight 594-conjugated tomato lectin from Lycopersicon esculentum agglutinin (LEA, 1:300; Vector Labs). After three washes in PBS, secondary antibodies were applied as necessary. All appropriate goat secondary antibodies (Alexa Fluor) were used at 1:200 dilution. Hoechst 33242 was used as nuclear counterstain. Slides were mounted in Mowiol after five PBS washes. Negative staining controls (primary or secondary antibodies alone) were used to obtain baseline image acquisition parameters. The latter were kept consistent for each fluorescent channel between slides and treatment conditions. The staining was done in one batch and the delay between mounting slides and image acquisition was kept to a minimum. Slides were randomly imaged by a single user to reduce any imaging bias, with five images per spinal cord, at $\times 20$ magnification on a on a Nikon Eclipse E800 microscope.

\section{Image analysis}

Image processing and analysis were performed using Adobe Photoshop CS6 and ImageJ64 software. The 32-bit fluorescent images acquired were downscaled in ImageJ to $25 \%$ of their original dimensions for feasibility of analysis, thresholded (based on negative control slides, using the Color Threshold function) and binarized. Using Photoshop CS6 and the image of a ruler acquired using the same protocol, images were cropped to include only a $5 \mathrm{~mm}$ rostrocaudal region surrounding the epicenter of the lesion site. Glial scar tissue interferes with fluorescent microscopy due to its high autofluorescence. Reliably removing this signal manually is challenging. Using the OR function in the Image Calculator, the overlapping area (corresponding to the auto-fluorescent signal) between images of different channels was determined. Using the SUBTRACT function in the Image Calculator, the computed autofluorescence was then subtracted from the thresholded images, respectively. The area of fluorescent staining was determined as a proportion of the total area (kept fixed) of the lesional and perilesional spinal cord corresponding to $5 \mathrm{~mm}$ of tissue. Any cavity was excluded during this measurement (http://rsbweb.nih.gov/ij/docs/guide/14630.html).

\section{Statistical analyses}

Statistical analyses were performed with GraphPad Prism software (La Jolla, CA). Each test is described in the 
corresponding figure legend. In short, differences among $\mathrm{CM}$ groups were assessed by one-way analysis of variance (ANOVA) with Dunnett's (for comparisons to HUCMC CM) post hoc, where the alpha threshold was set to 0.05 . Long-term (10 weeks post-SCI) neurobehavioral results were assessed by two-way ANOVA with Sidak's multiple comparisons post hoc test. The Brown-Forsythe test was used to compare standard deviations, confirming that parametric statistics are appropriate.

\section{Results}

\section{Antigenic profile of cells}

Passage-matched HUCMCs and BMSCs were morphologically similar (spindle-shaped) and proliferative (Supplementary Data). The majority of HUCMCs expressed the classical mesenchymal markers, including CD90, CD44, CD166, CD105, CD73, prolyl-4-hydroxylase, vimentin, collagen I, and alkaline phosphatase, but no hematopoietic
A

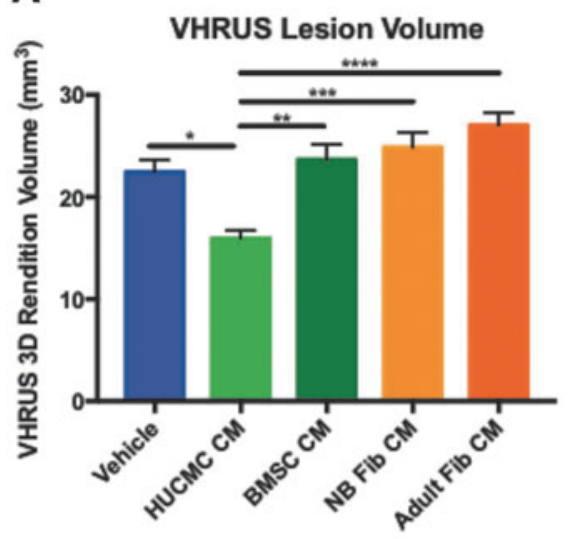

B

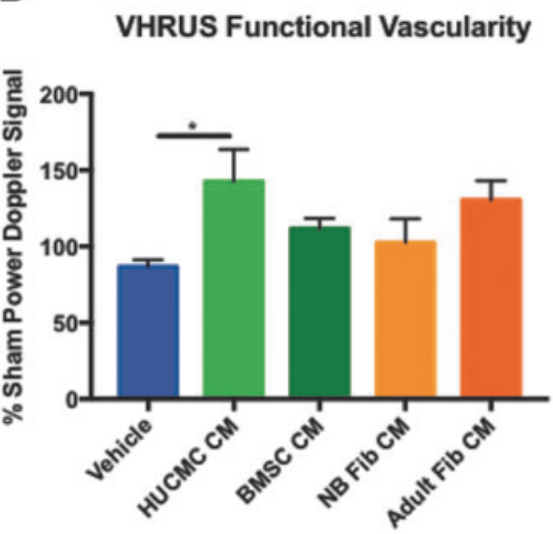

C
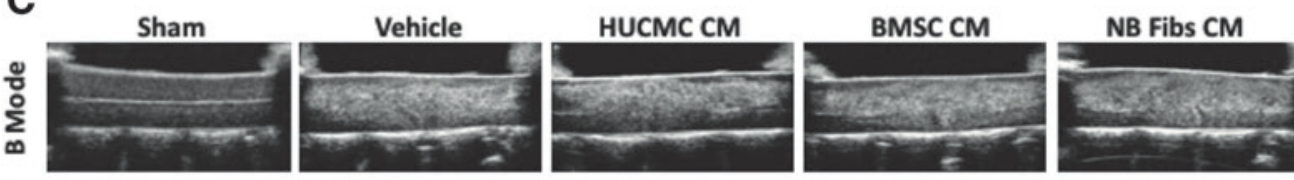

Adult Fibs CM

N/A
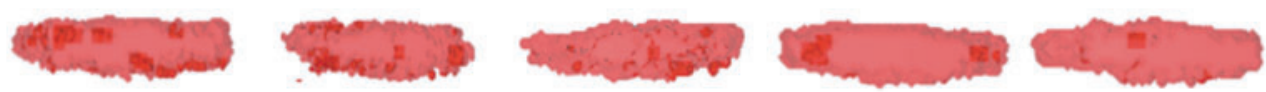

D

Vascular Permeability

E

Parenchymal Hemorrhage

$\mathbf{F}$

Neutrophil Infiltration
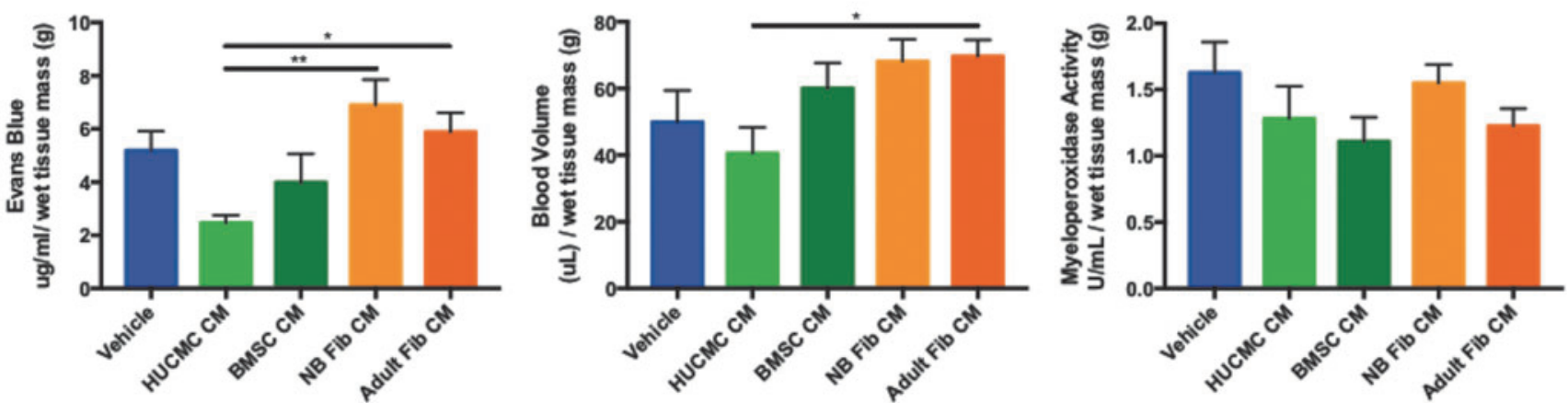

FIG. 1. Early intravenous infusion of HUCMC-derived CM significantly reduced acute ( $48 \mathrm{~h}$ post-SCI) vascular pathology compared to the CM of other cell sources. HUCMC CM reduced VHRUS quantified acute lesion volume (A) as well as Power Doppler determined functional vascularity (B) compared to that of a vehicle (media only) control ( $n=4-5$ per group). Representative VHRUS B-Mode sagittal slice images and three-dimensional lesion reconstructions are shown (C). Infusion of HUCMC CM did not affect vascular permeability as assessed by Evan's blue dye extravasation (D), parenchymal hemorrhage as assessed by the Drabkin's assay (E) and neutrophil infiltration $(\mathbf{F})$ as assessed by the MPO activity assay $(n=4-5$ per group). Data are expressed as mean \pm SEM. One-way analysis of variance (Dunnett's multiple comparison). * $P \leq 0.05$; $* * P \leq 0.01$; ***P $P 0.001$; $* * * * P \leq 0.0001$. CM, conditioned media; HUCMC, human umbilical cord matrix cell; MPO, myeloperoxidase; SCI, spinal cord injury; SEM, standard error of the mean; VHRUS, very high-resolution ultrasound imaging. Color images are available online. 
markers (CD45 and CD34, flow cytometry data in Supplementary Fig. S1). Most fibroblasts expressed prolyl-4hydroxylase and collagen I, while a proportion expressed the proliferative marker Ki67, but not the other antigenic markers tested (data not shown).

\section{Early intravenous infusion of HUCMC-derived CM reduced acute (48 $\mathrm{h}$ post-SCl) vascular pathology}

The efficacy of early intravenous infusion of MSCderived CM for traumatic SCI was assessed through an assortment of assays for vascular pathology. This additionally involved a comparison of CM form diverse cell sources, including HUCMCs, BMSCs, as well as NB and adult fibroblasts (Fig. 1). On most readouts, the early intravenous Infusion of HUCMC CM was more efficacious than other cell source CMs. Specifically, HUCMC CM infusion $\left(15.95 \pm 0.76 \mathrm{~mm}^{3}\right) \quad 7 \mathrm{~min}$ following SCI significantly $(P<0.02$, One-way ANOVA with Dunnett's multiple comparisons post hoc test) reduced the in vivo very high-resolution ultrasound imaging (VHRUS) quantified lesion volume compared to that of the vehicle control $\left(22.47 \pm 1.16 \mathrm{~mm}^{3}\right)$. There was also a statistically significant $(P<0.05$, one-way ANOVA with Dunnett's multiple comparisons post hoc test) rise in Power Doppler detection of lesional active blood flow (Fig. 1B) between HUCMC CM-treated animals $(142.6 \% \pm$ $6.07 \%$ of sham signal) and the vehicle control $(86.65 \% \pm$ $4.44 \%$ of sham signal). Interestingly, these changes did not translate into significant changes in vascular permeability (Fig. 1D; $P=0.11$ ), parenchymal hemorrhage (Fig. 1E; $P=0.80$ ) or neutrophil infiltration (Fig. $1 \mathrm{~F} ; P=0.52$ ) between vehicle and HUCMC CM treatment at $48 \mathrm{~h}$ post-SCI (one-way ANOVA with Dunnett's multiple comparisons post hoc test).

\section{PCA and cluster analysis of secretome reveals HUCMC-derived CM is unique}

PCA and hierarchical clustering analysis enabled a more accurate and thorough comparison of the CM from four cell types/sources (Fig. 2). The difference in the secretory capacity of the HUCMC secretome, compared to that of other cells, was less dramatic for angiogenesis factors, whereby HUCMCs had a similar secretory capacity (Fig. 2A; Cluster 3) of a unique repertoire compared to $\mathrm{NB}$ fibroblasts (Fig. 2A; Cluster \#4). Conversely, HUCMCs secreted a greater repertoire and quantity of most of the chemokines and cytokines relative to the other cells (Fig. 2B; Cluster \#2, Fig. 2C; Cluster \#4). In all cases, the PCA analysis revealed that HUCMCs stood far apart in the quantity and repertoire of factors secreted compared to the other cell types (Fig. 2A-C), while adult fibroblasts and BMSCs shared similar profiles in the angiogenesis and chemokine arrays
(Fig. 2A, B), and NB fibroblasts shared similar profiles with BMSCs in the cytokine array (Fig. 2C).

\section{HUCMC secretes factors that alter immune cell migration and the MAPK/ERK and JAK/STAT pathways}

Proteins that were highly secreted by HUCMCs in the three arrays were subjected to protein-protein interaction analysis (Clusters \#3, \#2, and \#4, from the angiogenesis, chemokine, and cytokine arrays, respectively). The analysis (Fig. 3) revealed that most of these proteins were strongly involved in leukocyte and lymphocyte trafficking, while also playing a role in the MAPK/ERK pathway. Another independent set of proteins was also found to be involved in the JAK/STAT signaling pathway.

\section{Early intravenous infusion of HUCMC-derived CM improved long-term (10 weeks post-SCI) tissue sparing without neurobehavioral recovery}

To evaluate the long-term effects of HUCMC CM infusion, the animals underwent weekly standardized neurobehavioral testing and histological analysis for/at 10 weeks following SCI (Fig. 4). Presacrificial VHRUS imaging (Fig. 4A, B) revealed a significant $(P<0.05$, unpaired twotailed $t$-test) reduction in spinal cord cavity volume between vehicle $\left(5.03 \pm 0.69 \mathrm{~mm}^{3}\right)$ and HUCMC CM-treated $(2.94 \pm$ $\left.0.55 \mathrm{~mm}^{3}\right)$ animals $(n=7-10$ per group). Although there was no statistically significant difference $(P=0.34$, unpaired two-tailed $t$-test) in glial scar (Fig. 4C), the extent of myelin (Fig. 4D) was greater $(P<0.05$, unpaired two-tailed $t$-test) in animals with HUCMC CM infusion $(10.61 \% \pm 1.39 \%$ area of staining) than the vehicle $(6.33 \% \pm 1.22 \%$ area of staining).

Weekly neurobehavioral testing included the grip strength (Fig. 4F), inclined plane (Fig. 4G), and BBB Locomotor Rating Scale (Fig. 4H) assessments ( $n=10$ per group). While there was no statistically significant difference between treated animals and controls for most of the functional tests (two-way ANOVA, Sidak's multiple comparison post hoc test), HUCMC CM animals had greater grip strength at 2 weeks post-SCI $(P<0.05)$. However, this effect was not preserved throughout the duration of neurobehavioral assessment.

\section{The acute vascular effects of early intravenous infusion of HUCMC CM dissipate by 10 weeks post-SCl}

Despite acute ( $48 \mathrm{~h}$ post-SCI) vasoprotective effects with HUCMC CM (Fig. 1A, B), there was no significant difference $(P=0.54)$ in vascularity (Fig. 5A) between vehicle $(27.61 \% \pm 3.33 \%$ area of staining) and HUCMC CM-infused

FIG. 2. PCA and hierarchical clustering reveals the unique secretory profile of HUCMCs. Multiplex protein arrays demonstrate that (A) HUCMCs secreted a unique profile of angiogenesis factors compared to BMSCs, NF, and AF; (B, C) HUCMCs had a dramatically increased secretory capacity of chemokines and cytokines compared to other cell types. PCA analysis was performed using the SVD method, and hierarchical clustering was done using correlation as a distance and average linkage in the row and columns. AF, adult fibroblasts; BMSCs, bone marrow mesenchymal stromal cells; NF, newborn fibroblasts; SVD, singular value decomposition. Color images are available online. 

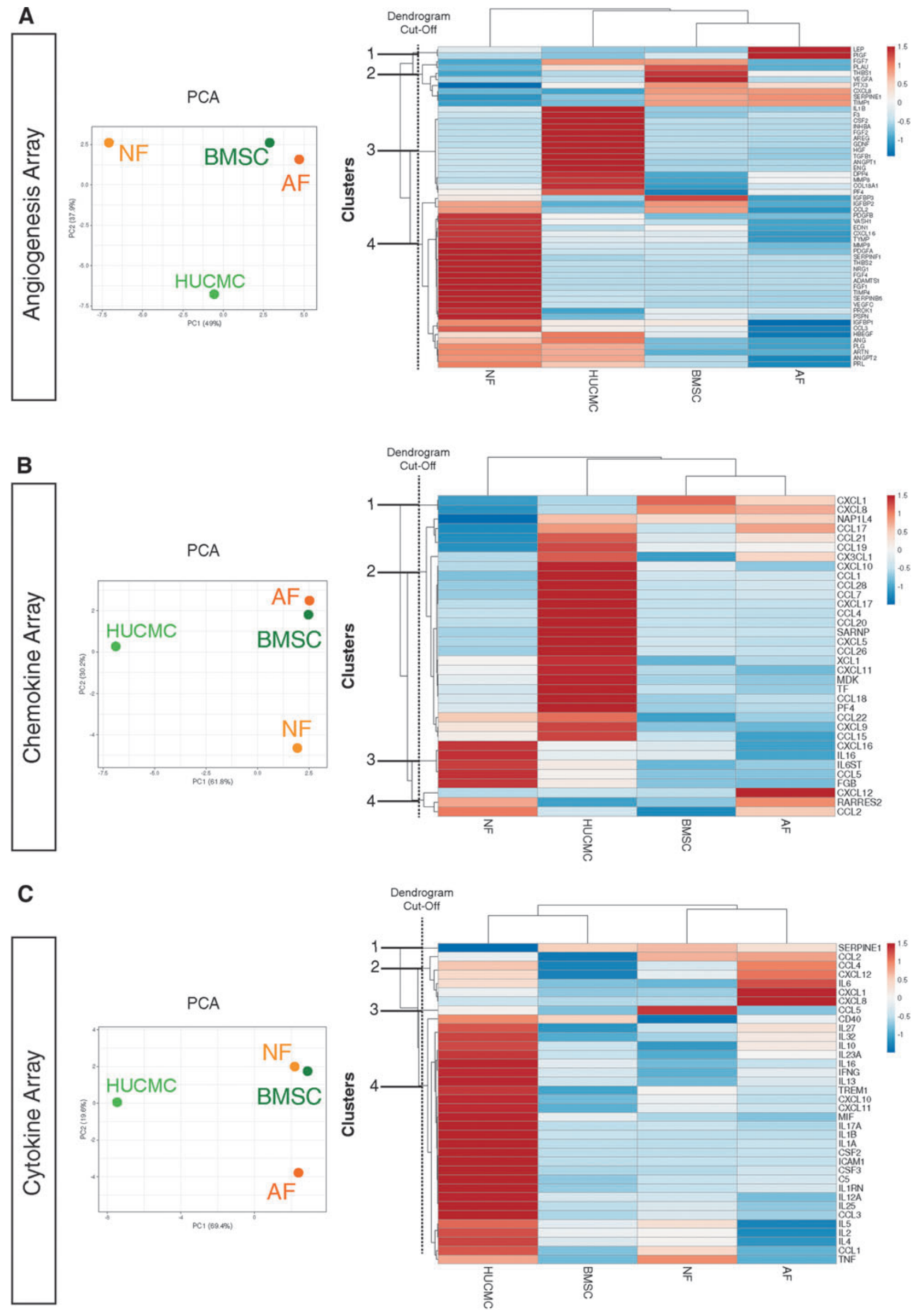


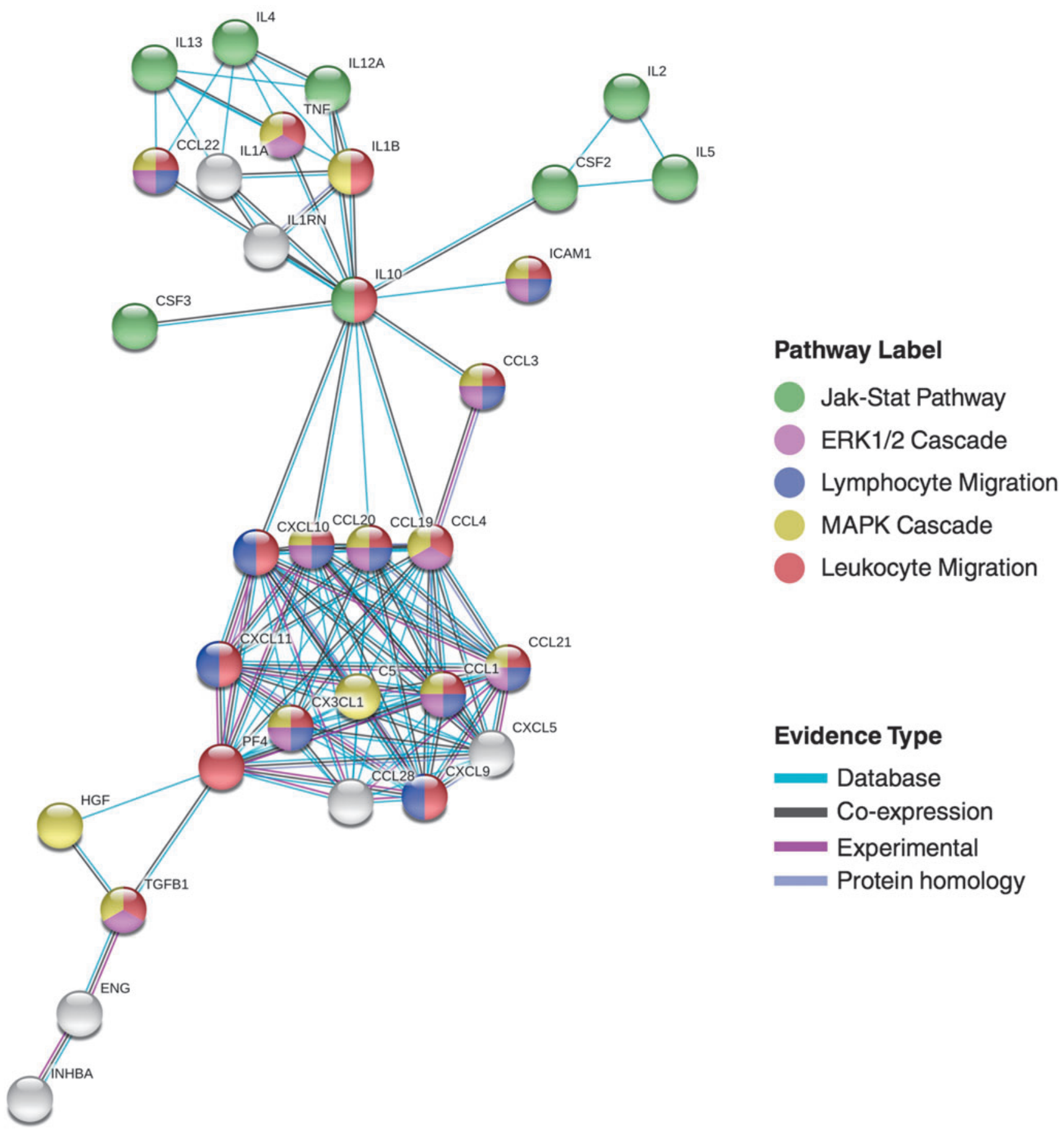

FIG. 3. Highly secreted factors by HUCMCs are involved in the JAK/STAT, MAPK/ERK, and immune cell trafficking pathways. Protein-protein interaction analysis and functional enrichment using gene ontology and Kyoto Encyclopedia of Genes and Genomes databases in STRING reveals that proteins secreted by HUCMCs are significantly $(P$-adjusted $<0.05)$ involved in pathways upregulated after traumatic SCI. Color images are available online.

animals $(23.44 \% \pm 5.5 \%$ area of staining). There was also no significance $(P=0.64)$ in Power Doppler detection of active blood flow (Fig. 5B, C) between vehicle $(40.13 \pm 2.22)$ and HUCMC CM-infused animals (41.83 \pm 2.80$)$.

\section{Discussion}

To our knowledge, this is one of the first reports of highthroughput profiling of secretomes from diverse mesen- chymal and fibroblastic lineage cells, and also the first time a concentrated secretome has been intravenously administered to target acute traumatic SCI pathology. Although proteomic analyses of MSC secretome have been previously reported [60,61], a comparative analysis of such a wide range of factors secreted by different age- and passagematched mesenchymal cells and fibroblasts has not been undertaken. Moreover, there have been only three studies to date examining the effects of MSC secretome in an 
A

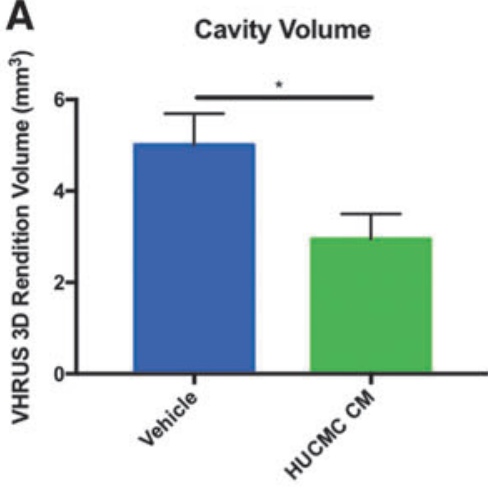

C

Gial Scar

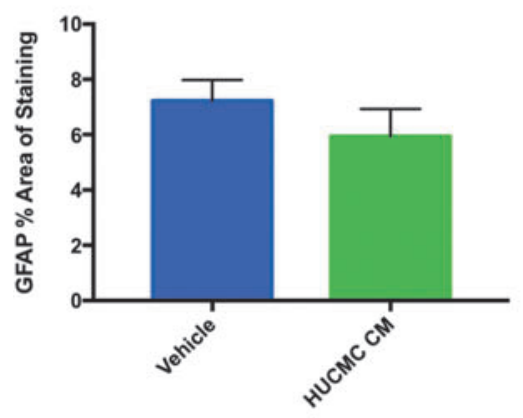

E
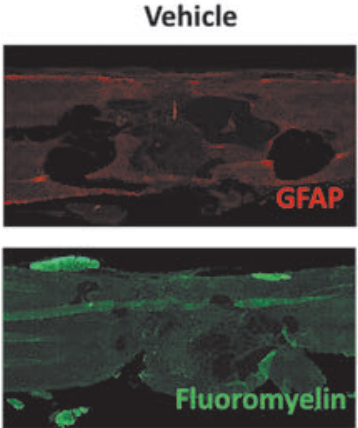

$\mathbf{F}$

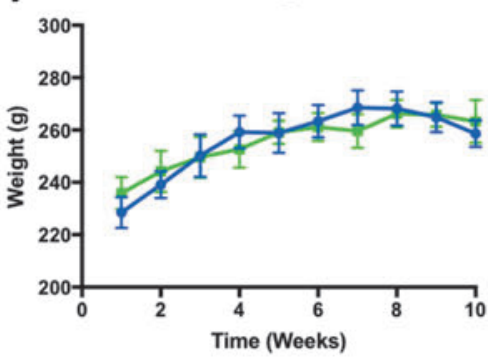

H

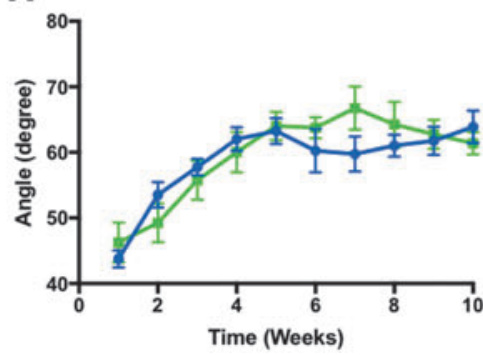

B

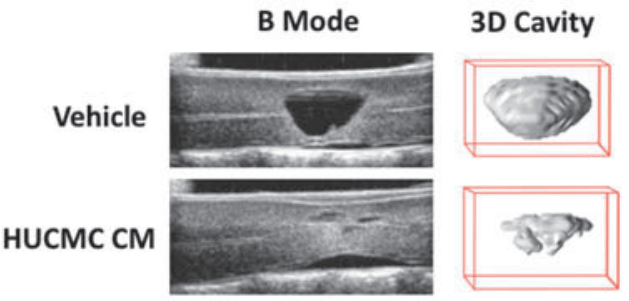

D

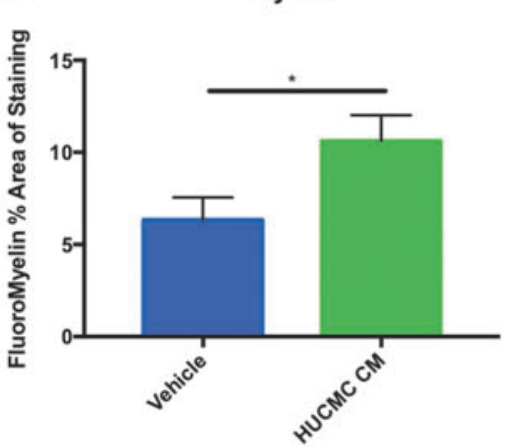

HUCMC CM

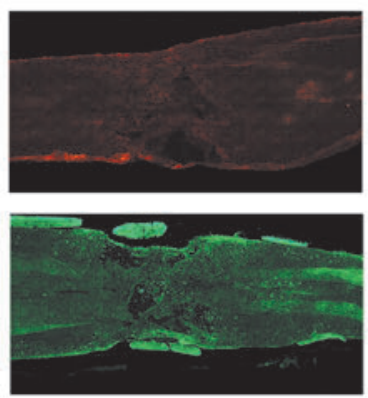

G

Grip Strength

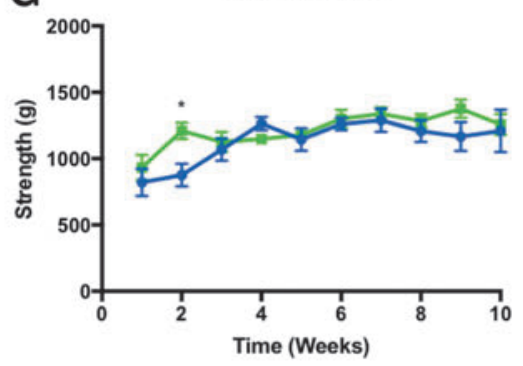

I

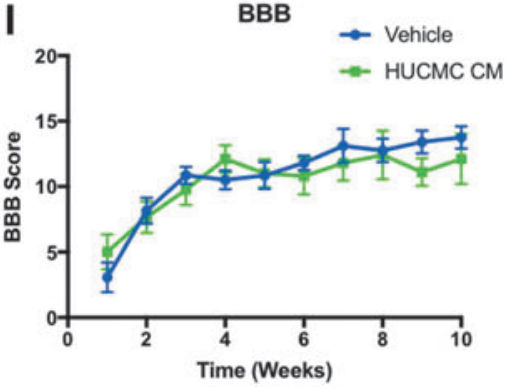

FIG. 4. Intravenous infusion of HUCMC-derived $\mathrm{CM}$ had reduced long-term (10 weeks post-SCI) cavitation and increased tissue sparing without significant changes to neurobehavioral recovery. Intravenous infusion of HUCMC CM significantly reduced VHRUS quantified spinal cord cavity volume (A). Data are expressed as mean \pm SEM $(P<0.05$, two-tailed unpaired $t$-test, $n=7-10$ per group). Representative VHRUS B-Mode sagittal slice images and three-dimensional cavity reconstructions are shown (B). Although there was no effect on glial scar (C), there was a significant increase in myelin preservation (D) as assessed by percent area of immunofluorescence staining with GFAP and FluoroMyelin, respectively. Data are expressed as mean \pm SEM (two-tailed unpaired $t$-test, $n=7-10$ per group). Representative images are shown (E). Weekly standardized behavioral testing was applied for 10 weeks after SCI and HUCMC CM infusion (vehicle, $n=10$; HUCMC $\mathrm{CM}, n=10$ ) by examiners blinded to the experimental groups (two-way analysis of variance, Sidak's multiple comparison post hoc test). Animals were weighed weekly (F); forelimb motor function was assessed with a grip strength meter (G); whole-body limb function as well as trunk stability was evaluated with the inclined plane test (H); and hindlimb locomotion was assessed by using the 22-point (0-21) Basso, Beattie, and Bresnahan Locomotor Rating Scale (I). Data are expressed as mean \pm SEM; $* P \leq 0.05$. Color images are available online. 
A

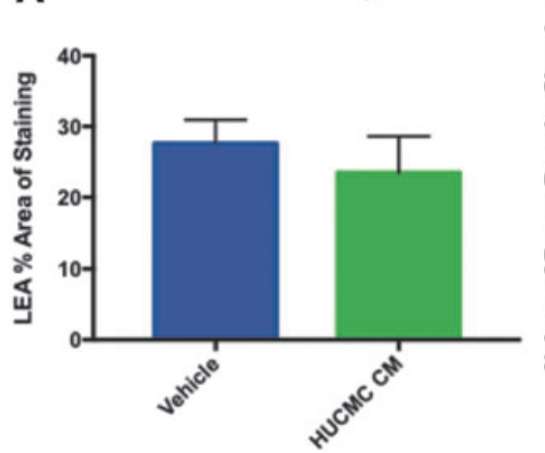

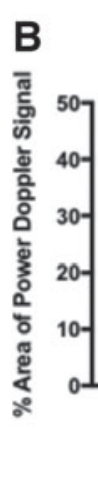

Functional Vascularity

C

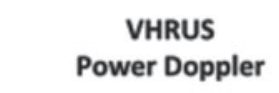

.

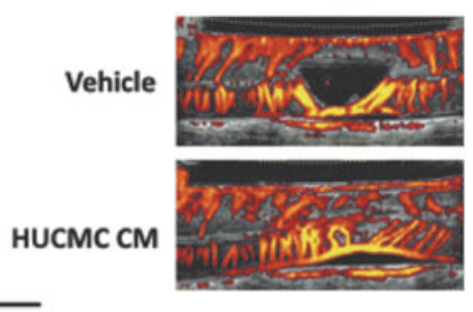

FIG. 5. The acute vasoprotective effects of HUCMC-derived CM infusion did not translate into long-term (10 weeks postSCI) vascular changes. There was no effect on vascularity as quantified by percent area of immunofluorescence staining (A) with DyLight 594-conjugated tomato lectin from LEA. There was also no effect on VHRUS Power Doppler determined functional vascularity (B). Representative VHRUS Power Doppler sagittal slice images are shown (C). Data are expressed as mean \pm SEM (two-tailed unpaired $t$-test, $n=6-9$ per group). LEA, Lycopersicon esculentum agglutinin. Color images are available online.

experimental in vivo model of CNS injury (two studies in traumatic brain injury and one study in SCI using unconcentrated rat secretome) [62-64]. Another study has examined MSC CM in an experimental autoimmune encephalomyelitis model, finding an effect on remyelination [65].

Here, we demonstrate that the secretome of HUCMCs is more effective, than that of BMSCs and fibroblasts (adult as well as NB), at reducing post-SCI secondary pathophysiology in a clinically relevant experimental model. At $48 \mathrm{~h}$ post-SCI, HUCMC CM significantly reduced lesion volume and improved functional vascularity. Interestingly, there was only modest effect on vascular permeability, parenchymal hemorrhage, and neutrophil infiltration. We also found that HUCMCs secreted greater concentrations of proangiogenic factors, anti-inflammatory cytokines, and neurotrophic factors than other cell types/sources. Unfortunately, even with repeated HUCMC CM infusion, the acute effects did not translate into long-term ( 10 weeks post$\mathrm{SCI}$ ) functional recovery, where we only saw a significant reduction in cavity volume and preservation of myelin. While this suggests that HUCMC CM may be insufficient as a standalone therapy, it could serve as part of a combinatorial strategy with other neuroprotective treatments (like Riluzole) [66]. Proteomic analysis suggests that the therapeutic effects of HUCMC CM may result from the modulation of the JAK/STAT, MAPK/ERK, and immune cell migratory pathways, although further work is required to optimize this approach for lasting effects.

The JAK-STAT, MAPK/ERK, and immune cell trafficking pathways are known to be activated after SCI [6774]. Importantly, inhibition of the JAK-STAT and MAPK/ ERK pathways has been shown to have both detrimental and beneficial effects on SCI $[67,69,70]$. Our protein interaction analysis predicts that both pathways were possibly modulated exclusively by HUCMC CM infusion. Therefore, this regulation may underlie the in vivo vascular effects observed and has been previously associated with other models of MSC secretome infusion [75], where JAK-STAT pathway has been shown to underlie mouse liver regeneration after the administration of hypoxic CM from human adipose-derived stem cells [76].
While it is clear that the JAK-STAT and toll-like receptor (TLR) pathway effects in our model require further investigation, there are also likely multiple mechanisms at play. For instance, there are also greater quantities of and/or different extracellular matrix (ECM) proteins in HUCMC secretome compared to those of other cells. We have observed that the viscosity of HUCMC CM is higher than that of the other cells used in this study, making it very difficult to filter through a $0.2 \mu \mathrm{m}$ pore size filter, unlike the culture media of other cells. These HUCMC-derived ECM proteins could underlie a greater and/or more rapid isolation of the lesion epicenter, thereby limiting the spread of secondary damage. This has been reported in the application of adipose MSCs after SCI, where the neuroprotective effects were attributed to their secretion of laminin [77]. In addition, ECM proteins have been shown to influence the survival of endothelial as well as neural cells [78-80].

Through further assessment of the secretome profiles, we also identified the factors that were expressed more highly by HUCMCs or the other cells. Specifically, we found that enhanced vascular permeability and lesion volume were associated with the secretion of greater amounts of proinflammatory cytokines and VEGF (which is known to not only promote neovascularization but also increase vascular permeability). Relatedly, reduced vascular permeability and lesions were linked to greater concentrations of secreted FGF2 in HUCMC CM (which promotes vascular stabilization and reduces vascular permeability after experimental stroke [81]) and lower amounts of proinflammatory cytokines. A notable exception to this trend was the higher expression of the proinflammatory cytokines IL1-a and IL-1b by HUCMCs relative to other cells (but also greater secretion of IL-1ra by HUCMCs).

As another alternative potential mechanism, the large concentrations of G-CSF and GM-CSF secreted by HUCMCs may also mobilize endogenous MSCs and HSCs from their niche in bone marrow. These could further contribute to suppressing secondary pathology, considering that GM-CSF has been implicated in the transformation of proinflammatory M1 microglia to anti-inflammatory M2 microglia [82-84]. GM-CSF was analysed in two arrays (cytokine and 
angiogenesis factors). The similarly high levels of expression in both arrays support the finding. Therefore, future work should explore differences in microglial populations.

Recently, there has also been growing interest in MSCderived extracellular vesicles, known as exosomes, and their role in MSC-mediated effects [85]. Several reports have been able to recapitulate the biological activity of MSCs by using exosomes alone $[44,86,87]$, which encapsulate diverse combinations of cytokines/growth factors/RNAs and miRNAs. Furthermore, as previous studies have shown that exosomes may vary depending upon the source of MSCs [88], the differences described in this work may also be a consequence of exosomes. Therefore, characterization of exosomes within the concentrated CM is an essential next step.

From a technical perspective, we chose to condition medium from cultured HUCMCs under serum-free conditions, given a previous report of enhanced MSC angiogenic capacity without serum [89]. The concentrated secretomes in this study were stored at $-80^{\circ} \mathrm{C}$ and $\mathrm{HUCMC}$ secretome samples were profiled by cytokine ELISA almost a year apart with the same results, demonstrating their storage stability. This is in contrast to frozen live cells, which require cryogenic storage temperatures below $-123^{\circ} \mathrm{C}$ for the maintenance of post-thaw viability. The application of lyophilization technology and other protein stabilization agents is anticipated to enable the minimum storage temperature to be increased to $-20^{\circ} \mathrm{C}$ or even higher. This would not only reduce the cost and practicalities of this approach over live cells but also enable administration as a first-aid measure after SCI. Moreover, the therapeutic potential of this approach is worth highlighting, as lyophilized secretome could be stored long-term for future use.

Despite our best efforts, this study is not without limitations. Specifically, maintaining batch consistency and dosing paradigms of paracrine factors for production of therapeutic concentrated CM is particularly challenging. Cell secretions are a product of cell source, passage, density, and incubation times [35]. Although we applied passage-matched cells, plated at the same density and in the same growth conditions, this work is also susceptible to these shortcomings. For this reason, future work should include a comparison of culture conditions on secretome among different cell sources and use multiple cell lines. This is especially important in comparing our results with others in field, many of which show success with BMSCderived CM [90-93]. Ideally, with greater characterization, we will be able to identify the active molecules in CM and generate a consistent therapeutic cocktail. It will also be important for future studies to generate a more detailed histological analysis, particularly with regard to the glial scar, remyelination, and vascularity changes identified through this work.

\section{Conclusions}

This high-throughput secretome comparison allows the choice of the cell source to be optimized and tailored for specific pathology. Yet, intravenous infusion of the HUCMC secretome was found to be most effective at limiting vascular damage post-SCI, potentially through the modulation of the JAK-STAT and TLR signaling pathways. This "secretotherapeutic" strategy represents a novel and minimally invasive method to target multiple organ systems and several pathologies shortly after traumatic SCI
[60,94,95]. Our findings have important implications for traumatic CNS injuries given the logistical and practical advantages of secretome over live cells, including rapid administration post-injury, unlike live cells, which need days if not weeks of preparation. Although the acute effects did not translate into long-term improvements in functional recovery, this approach represents an addition to the arsenal of treatment options for CNS injuries that is likely to be complementary through coadministration [2,96-99]. Therefore, the application of secretotherapy and subsequent live-cell therapy or even pharmaceuticals is not mutually exclusive. In fact, the acute administration of concentrated secretome to control VD could conceivably be combined with a later administration of live cells or pharmaceuticals to target secondary injury, including inflammation.

\section{Acknowledgments}

Many thanks also to Dr. Madeleine O'Higgins for article review and editing, and to Dr. Timothy Allsopp and Dr. Joshua Duckworth (and others at Neusentis) for technical support with ELISA arrays. Special thanks to Dr. Jian Wang, Dr. Behzad Azad (Fehlings Lab), and Mr. Frank Vidic (UHN) for other technical support.

\section{Author Disclosure Statement}

The authors have nothing to disclose.

\section{Funding Information}

This study was generously supported by the See the Potential Fellowship from the Stem Cell Network (SCN) and Pfizer/Neusentis (R.V.) and the SCN Undergraduate Research Training Award (M.M.). Additional support was provided by the Canadian Institutes of Health Research Training Program in Regenerative Medicine fellowship (A.B.), as well as the Ontario Graduate Scholarship (A.B. and J.H.). M.G.F. holds the Gerald and Tootsie Halbert Chair in Neural Repair and Regeneration.

\section{Supplementary Material}

Supplementary Data

Supplementary Figure S1

\section{References}

1. Tator CH and MG Fehlings. (1991). Review of the secondary injury theory of acute spinal cord trauma with emphasis on vascular mechanisms. J Neurosurg 75:15-26.

2. Fehlings MG. (2013). Mesenchymal cells in the treatment of spinal cord injury: current \& future perspectives. Curr Stem Cell Res Ther 8:25-38.

3. Sinden JD, I Vishnubhatla and KW Muir. (2012). Prospects for stem cell-derived therapy in stroke. Prog Brain Res 201: 119-167.

4. Fehlings MG and R Vawda. (2011). Cellular treatments for spinal cord injury: the time is right for clinical trials. Neurother J Am Soc Exp Neurother 8:704-720.

5. Caplan AI. (2008). All MSCs are pericytes? Cell Stem Cell 3:229-230.

6. Chen C-W, E Montelatici, M Crisan, M Corselli, J Huard, L Lazzari and B Péault. (2009). Perivascular multi-lineage 
progenitor cells in human organs: regenerative units, cytokine sources or both? Cytokine Growth Factor Rev 20:429-434.

7. Corselli M, C-W Chen, M Crisan, L Lazzari and B Péault. (2010). Perivascular ancestors of adult multipotent stem cells. Arterioscler Thromb Vasc Biol 30:1104-1109.

8. Corselli M, M Crisan, IR Murray, CC West, J Scholes, F Codrea, N Khan and B Péault. (2013). Identification of perivascular mesenchymal stromal/stem cells by flow cytometry. Cytom Part J Int Soc Anal Cytol 83:714-720.

9. Crisan M, C-W Chen, M Corselli, G Andriolo, L Lazzari and B Péault. (2009). Perivascular multipotent progenitor cells in human organs. Ann N Y Acad Sci 1176:118-123.

10. Crisan M, M Corselli, C-W Chen and B Péault. (2011). Multilineage stem cells in the adult: a perivascular legacy? Organogenesis 7:101-104.

11. Crisan M, M Corselli, WCW Chen and B Péault. (2012). Perivascular cells for regenerative medicine. J Cell Mol Med 16:2851-2860.

12. Baust JM, MJ Vogel, R Van Buskirk and JG Baust. (2001). A molecular basis of cryopreservation failure and its modulation to improve cell survival. Cell Transplant 10: 561-571.

13. Corwin WL, JM Baust, JG Baust and RG Van Buskirk. (2014). Characterization and modulation of human mesenchymal stem cell stress pathway response following hypothermic storage. Cryobiology 68:215-226.

14. Kang E-S, K-Y Ha and Y-H Kim. (2012). Fate of transplanted bone marrow derived mesenchymal stem cells following spinal cord injury in rats by transplantation routes. J Korean Med Sci 27:586-593.

15. Furlani D, M Ugurlucan, L Ong, K Bieback, E Pittermann, I Westien, W Wang, C Yerebakan, W Li, et al. (2009). Is the intravascular administration of mesenchymal stem cells safe? Mesenchymal stem cells and intravital microscopy. Microvasc Res 77:370-376.

16. Lalu MM, L McIntyre, C Pugliese, D Fergusson, BW Winston, JC Marshall, J Granton and DJ Stewart; Canadian Critical Care Trials Group. (2012). Safety of cell therapy with mesenchymal stromal cells (SafeCell): a systematic review and meta-analysis of clinical trials. PLoS One 7:e47559.

17. Stylianou J, M Vowels and K Hadfield. (2006). Novel cryoprotectant significantly improves the post-thaw recovery and quality of HSC from CB. Cytotherapy 8:57-61.

18. Nicoud IB, DM Clarke, G Taber, KM Stolowski, SE Roberge, MK Song, AJ Mathew and J-A Reems. (2012). Cryopreservation of umbilical cord blood with a novel freezing solution that mimics intracellular ionic composition. Transfusion (Paris) 52:2055-2062.

19. Malpique R, LM Osório, DS Ferreira, F Ehrhart, C Brito, H Zimmermann and PM Alves. (2010). Alginate encapsulation as a novel strategy for the cryopreservation of neurospheres. Tissue Eng Part C Methods 16:965-977.

20. Malpique R, F Ehrhart, A Katsen-Globa, H Zimmermann and PM Alves. (2009). Cryopreservation of adherent cells: strategies to improve cell viability and function after thawing. Tissue Eng Part C Methods 15:373-386.

21. Clarke DM, DJ Yadock, IB Nicoud, AJ Mathew and S Heimfeld. (2009). Improved post-thaw recovery of peripheral blood stem/progenitor cells using a novel intracellular-like cryopreservation solution. Cytotherapy 11:472-479.

22. Baust JM, Van Buskirk and JG Baust. (2000). Cell viability improves following inhibition of cryopreservation-induced apoptosis. In Vitro Cell Dev Biol Anim 36:262-270.
23. Al-Saqi SH, M Saliem, HC Quezada, A Ekblad, AF Jonasson, O Hovatta and C Götherström. (2015). Defined serum- and xeno-free cryopreservation of mesenchymal stem cells. Cell Tissue Bank 16:181-193.

24. Naaldijk Y, M Staude, V Fedorova and A Stolzing. (2012). Effect of different freezing rates during cryopreservation of rat mesenchymal stem cells using combinations of hydroxyethyl starch and dimethylsulfoxide. BMC Biotechnol 12:49.

25. Baust JM, R Van Buskirk and JG Baust. (2002). Modulation of the cryopreservation cap: elevated survival with reduced dimethyl sulfoxide concentration. Cryobiology 45:97-108.

26. Baust JG, D Gao and JM Baust. (2009). Cryopreservation: an emerging paradigm change. Organogenesis 5:90-96.

27. Moll G, JJ Alm, LC Davies, L von Bahr, N Heldring, L Stenbeck-Funke, OA Hamad, R Hinsch, L Ignatowicz, et al. (2014). Do cryopreserved mesenchymal stromal cells display impaired immunomodulatory and therapeutic properties? Stem Cells 32:2430-2442.

28. Chinnadurai R, MA Garcia, Y Sakurai, WA Lam, AD Kirk, J Galipeau and IB Copland. (2014). Actin cytoskeletal disruption following cryopreservation alters the biodistribution of human mesenchymal stromal cells in vivo. Stem Cell Reports 3:60-72.

29. Lopatina T, S Bruno, C Tetta, N Kalinina, M Porta and G Camussi. (2014). Platelet-derived growth factor regulates the secretion of extracellular vesicles by adipose mesenchymal stem cells and enhances their angiogenic potential. Cell Commun Signal 12:26.

30. Liang X, Y Ding, Y Zhang, H-F Tse and Q Lian. (2014). Paracrine mechanisms of mesenchymal stem cell-based therapy: current status and perspectives. Cell Transplant 23: 1045-1059.

31. Millard SM and NM Fisk. (2013). Mesenchymal stem cells for systemic therapy: shotgun approach or magic bullets? BioEssays News Rev Mol Cell Dev Biol 35:173-182.

32. Lavoie JR and M Rosu-Myles. (2013). Uncovering the secretes of mesenchymal stem cells. Biochimie 95:2212-2221.

33. Madrigal M, KS Rao and NH Riordan. (2014). A review of therapeutic effects of mesenchymal stem cell secretions and induction of secretory modification by different culture methods. J Transl Med 12:260.

34. Phinney DG and MF Pittenger. (2017). Concise review: MSC-derived exosomes for cell-free therapy. Stem Cells 35:851-858.

35. Ferreira JR, GQ Teixeira, SG Santos, MA Barbosa, G Almeida-Porada and RM Gonçalves. (2018). Mesenchymal stromal cell secretome: influencing therapeutic potential by cellular pre-conditioning. Front Immunol 9:2837.

36. Badner A, R Vawda, A Laliberte, J Hong, M Mikhail, A Jose, R Dragas and M Fehlings. (2016). Early intravenous delivery of human brain stromal cells modulates systemic inflammation and leads to vasoprotection in traumatic spinal cord injury. Stem Cells Transl Med 5:991-1003.

37. Badner A, J Hacker, J Hong, M Mikhail, R Vawda and MG Fehlings. (2018). Splenic involvement in umbilical cord matrix-derived mesenchymal stromal cell-mediated effects following traumatic spinal cord injury. J Neuroinflammation 15:219.

38. Vawda R, A Badner, J Hong, M Mikhail, A Lakhani, R Dragas, K Xhima, T Barretto, CL Librach and MG Fehlings. (2019). Early intravenous infusion of mesenchymal stromal cells exerts a tissue source age-dependent beneficial effect on neurovascular integrity and neurobehavioral 
recovery after traumatic cervical spinal cord injury. Stem Cells Transl Med 8:639-649.

39. Davies JE, JT Walker and A Keating. (2017). Concise review: Wharton's Jelly: the rich, but enigmatic, source of mesenchymal stromal cells. Stem Cells Transl Med 6: 1620-1630.

40. Nekanti U, S Dastidar, P Venugopal, S Totey and M Ta. (2010). Increased proliferation and analysis of differential gene expression in human Wharton's jelly-derived mesenchymal stromal cells under hypoxia. Int J Biol Sci 6:499-512.

41. Angoulvant D, F Ivanes, R Ferrera, PG Matthews, S Nataf and M Ovize. (2011). Mesenchymal stem cell conditioned media attenuates in vitro and ex vivo myocardial reperfusion injury. J Heart Lung Transplant 30:95-102.

42. Cargnoni A, L Ressel, D Rossi, A Poli, D Arienti, G Lombardi and O Parolini. (2012). Conditioned medium from amniotic mesenchymal tissue cells reduces progression of bleomycin-induced lung fibrosis. Cytotherapy 14: 153-161.

43. Fidelis-de-Oliveira P, JPS Werneck-de-Castro, V PinhoRibeiro, BCM Shalom, JH Nascimento-Silva, RH Costa e Souza, IS Cruz, RR Rangel, RCS Goldenberg and AC Campos-de-Carvalho. (2012). Soluble factors from multipotent mesenchymal stromal cells have antinecrotic effect on cardiomyocytes in vitro and improve cardiac function in infarcted rat hearts. Cell Transplant 21:1011-1021.

44. Lai RC, F Arslan, MM Lee, NSK Sze, A Choo, TS Chen, M Salto-Tellez, L Timmers, CN Lee, et al. (2010). Exosome secreted by MSC reduces myocardial ischemia/reperfusion injury. Stem Cell Res 4:214-222.

45. Mirabella T, J Hartinger, C Lorandi, C Gentili, M van Griensven and R Cancedda. (2012). Proangiogenic soluble factors from amniotic fluid stem cells mediate the recruitment of endothelial progenitors in a model of ischemic fasciocutaneous flap. Stem Cells Dev 21:2179-2188.

46. Timmers L, SK Lim, IE Hoefer, F Arslan, RC Lai, AAM van Oorschot, MJ Goumans, C Strijder, SK Sze, et al. (2011). Human mesenchymal stem cell-conditioned medium improves cardiac function following myocardial infarction. Stem Cell Res 6:206-214.

47. Kilkenny C and DG Altman. (2010). Improving bioscience research reporting: ARRIVE-ing at a solution. Lab Anim 44:377-378.

48. Kilkenny C, W Browne, IC Cuthill, M Emerson and DG Altman; NC3Rs Reporting Guidelines Working Group. (2010). Animal research: reporting in vivo experiments: the ARRIVE guidelines. Br J Pharmacol 160:1577-1579.

49. Kilkenny C, WJ Browne, IC Cuthill, M Emerson and DG Altman. (2010). Improving bioscience research reporting: the ARRIVE guidelines for reporting animal research. PLoS Biol 8:e1000412.

50. McGrath JC, GB Drummond, EM McLachlan, C Kilkenny and CL Wainwright. (2010). Guidelines for reporting experiments involving animals: the ARRIVE guidelines. Br J Pharmacol 160:1573-1576.

51. Soubeyrand M, A Badner, R Vawda, YS Chung and MG Fehlings. (2014). Very high resolution ultrasound imaging for real-time quantitative visualization of vascular disruption after spinal cord injury. J Neurotrauma 31:1767-1775.

52. Dubory A, E Laemmel, A Badner, J Duranteau, E Vicaut, C Court and M Soubeyrand. (2015). Contrast enhanced ultrasound imaging for assessment of spinal cord blood flow in experimental spinal cord injury. J Vis Exp 7:e52536.
53. Badner A, PM Vidal, J Hong, J Hacker and MG Fehlings. (2019). Endogenous interleukin-10 deficiency exacerbates vascular pathology in traumatic cervical spinal cord injury. J Neurotrauma 36:2298-2307.

54. Ikeda Y, M Wang and S Nakazawa. (1994). Simple quantitative evaluation of blood-brain barrier disruption in vasogenic brain edema. Acta Neurochir Suppl (Wien) 60:119-120.

55. Raudvere U, L Kolberg, I Kuzmin, T Arak, P Adler, H Peterson and J Vilo. (2019). g:Profiler: a web server for functional enrichment analysis and conversions of gene lists (2019 update). Nucleic Acids Res 47:W191-W198.

56. Metsalu T and J Vilo. (2015). ClustVis: a web tool for visualizing clustering of multivariate data using Principal Component Analysis and heatmap. Nucleic Acids Res 43: W566-W570.

57. Szklarczyk D, AL Gable, D Lyon, A Junge, S Wyder, J Huerta-Cepas, M Simonovic, NT Doncheva, JH Morris, et al. (2019). STRING v11: protein-protein association networks with increased coverage, supporting functional discovery in genome-wide experimental datasets. Nucleic Acids Res 47:D607-D613.

58. Forgione N, SK Karadimas, WD Foltz, K Satkunendrarajah, A Lip and MG Fehlings. (2014). Bilateral contusioncompression model of incomplete traumatic cervical spinal cord injury. J Neurotrauma 31:1776-1788.

59. Basso DM, MS Beattie and JC Bresnahan. (1995). A sensitive and reliable locomotor rating scale for open field testing in rats. J Neurotrauma 12:1-21.

60. Kim H-S, D-Y Choi, SJ Yun, S-M Choi, JW Kang, JW Jung, D Hwang, KP Kim and D-W Kim. (2012). Proteomic analysis of microvesicles derived from human mesenchymal stem cells. J Proteome Res 11:839-849.

61. Burrows GG, W Van't Hof, LF Newell, A Reddy, PA Wilmarth, LL David, A Raber, A Bogaerts, J Pinxteren, RJ Deans and RT Maziarz. (2013). Dissection of the human multipotent adult progenitor cell secretome by proteomic analysis. Stem Cells Transl Med 2:745-757.

62. Chang C-P, C-C Chio, C-U Cheong, C-M Chao, B-C Cheng and M-T Lin. (2013). Hypoxic preconditioning enhances the therapeutic potential of the secretome from cultured human mesenchymal stem cells in experimental traumatic brain injury. Clin Sci (Lond) 1979 124:165-176.

63. Chuang T-J, K-C Lin, C-C Chio, C-C Wang, C-P Chang and J-R Kuo. (2012). Effects of secretome obtained from normoxia-preconditioned human mesenchymal stem cells in traumatic brain injury rats. J Trauma Acute Care Surg 73:1161-1167.

64. Cantinieaux D, R Quertainmont, S Blacher, L Rossi, T Wanet, A Noël, G Brook, J Schoenen and R Franzen. (2013). Conditioned medium from bone marrow-derived mesenchymal stem cells improves recovery after spinal cord injury in rats: an original strategy to avoid cell transplantation. PLoS One 8:e69515.

65. Bai L, DP Lennon, AI Caplan, A DeChant, J Hecker, J Kranso, A Zaremba and RH Miller. (2012). Hepatocyte growth factor mediates mesenchymal stem cell-induced recovery in multiple sclerosis models. Nat Neurosci 15:862-870.

66. Ulndreaj A, A Badner and MG Fehlings. (2017). Promising neuroprotective strategies for traumatic spinal cord injury with a focus on the differential effects among anatomical levels of injury. F1000Res 6:1907.

67. Song Y, Z Zeng, C Jin, J Zhang, B Ding and F Zhang. (2013). Protective effect of ginkgolide B against acute 
spinal cord injury in rats and its correlation with the Jak/ STAT signaling pathway. Neurochem Res 38:610-619.

68. Wang T, W Yuan, Y Liu, Y Zhang, Z Wang, X Zhou, G Ning, L Zhang, L Yao, S Feng and X Kong. (2015). The role of the JAK-STAT pathway in neural stem cells, neural progenitor cells and reactive astrocytes after spinal cord injury. Biomed Rep 3:141-146.

69. Yamauchi K, K Osuka, M Takayasu, N Usuda, A Nakazawa, N Nakahara, M Yoshida, C Aoshima, M Hara and J Yoshida. (2006). Activation of JAK/STAT signalling in neurons following spinal cord injury in mice. $\mathrm{J}$ Neurochem 96:1060-1070.

70. Zu J, Y Wang, G Xu, J Zhuang, H Gong and J Yan. (2014). Curcumin improves the recovery of motor function and reduces spinal cord edema in a rat acute spinal cord injury model by inhibiting the JAK/STAT signaling pathway. Acta Histochem 116:1331-1336.

71. Liu T, F-J Cao, D-D Xu, Y-Q Xu and S-Q Feng. (2015). Upregulated Ras/Raf/ERK1/2 signaling pathway: a new hope in the repair of spinal cord injury. Neural Regen Res 10:792-796.

72. Crown ED, Z Ye, KM Johnson, G-Y Xu, DJ McAdoo and CE Hulsebosch. (2006). Increases in the activated forms of ERK 1/2, p38 MAPK, and CREB are correlated with the expression of at-level mechanical allodynia following spinal cord injury. Exp Neurol 199:397-407.

73. Ghasemlou N, R Lopez-Vales, C Lachance, T Thuraisingam, M Gaestel, D Radzioch and S David. (2010). Mitogen-activated protein kinase-activated protein kinase 2 (MK2) contributes to secondary damage after spinal cord injury. J Neurosci 30:13750-13759.

74. Trivedi A, AD Olivas and LJ Noble-Haeusslein. (2006). Inflammation and spinal cord injury: infiltrating leukocytes as determinants of injury and repair processes. Clin Neurosci Res 6:283-292.

75. Ranganath SH, O Levy, MS Inamdar and JM Karp. (2012). Harnessing the mesenchymal stem cell secretome for the treatment of cardiovascular disease. Cell Stem Cell 10:244 258.

76. Lee SC, HJ Jeong, SK Lee and S-J Kim. (2016). Hypoxic conditioned medium from human adipose-derived stem cells promotes mouse liver regeneration through JAK/ STAT3 signaling. Stem Cells Transl Med 5:816-825.

77. Menezes K, MA Nascimento, JP Gonçalves, AS Cruz, DV Lopes, B Curzio, M Bonamino, JRL de Menezes, R Borojevic, MID Rossi and T Coelho-Sampaio. (2014). Human mesenchymal cells from adipose tissue deposit laminin and promote regeneration of injured spinal cord in rats. PLoS One 9:e96020.

78. Delaney CE, BT Weagant and CL Addison. (2006). The inhibitory effects of endostatin on endothelial cells are modulated by extracellular matrix. Exp Cell Res 312:24762489.

79. Aizman I, CC Tate, M McGrogan and CC Case. (2009). Extracellular matrix produced by bone marrow stromal cells and by their derivative, SB623 cells, supports neural cell growth. J Neurosci Res 87:3198-3206.

80. Aizman I, BJ Tirumalashetty, M McGrogan and CC Case. (2014). Comparison of the neuropoietic activity of gene-modified versus parental mesenchymal stromal cells and the identification of soluble and extracellular matrix-related neuropoietic mediators. Stem Cell Res Ther 5:29.
81. Huang B, PR Krafft, Q Ma, WB Rolland, B Caner, T Lekic, A Manaenko, M Le, J Tang and JH Zhang. (2012). Fibroblast growth factors preserve blood-brain barrier integrity through RhoA inhibition after intracerebral hemorrhage in mice. Neurobiol Dis 46:204-214.

82. Durafourt BA, CS Moore, DA Zammit, TA Johnson, F Zaguia, M-C Guiot, A Bar-Or and JP Antel. (2012). Comparison of polarization properties of human adult microglia and blood-derived macrophages. Glia 60:717727.

83. Gabrusiewicz K, A Ellert-Miklaszewska, M Lipko, M Sielska, M Frankowska and B Kaminska. (2011). Characteristics of the alternative phenotype of microglia/macrophages and its modulation in experimental gliomas. PLoS One 6:e23902.

84. Sielska M, P Przanowski, B Wylot, K Gabrusiewicz, M Maleszewska, M Kijewska, M Zawadzka, J Kucharska, K Vinnakota, et al. (2013). Distinct roles of CSF family cytokines in macrophage infiltration and activation in glioma progression and injury response. J Pathol 230:310-321.

85. Mendt M, K Rezvani and E Shpall. (2019). Mesenchymal stem cell-derived exosomes for clinical use. Bone Marrow Transplant 54:789-792.

86. Lou G, Z Chen, M Zheng and Y Liu. (2017). Mesenchymal stem cell-derived exosomes as a new therapeutic strategy for liver diseases. Exp Mol Med 49:e346.

87. Bruno S, C Grange, MC Deregibus, RA Calogero, S Saviozzi, F Collino, L Morando, A Busca, M Falda, et al. (2009). Mesenchymal stem cell-derived microvesicles protect against acute tubular injury. J Am Soc Nephrol 20:1053-1067.

88. Börger V, M Bremer, R Ferrer-Tur, L Gockeln, O Stambouli, A Becic and B Giebel. (2017). Mesenchymal stem/ stromal cell-derived extracellular vesicles and their potential as novel immunomodulatory therapeutic agents. Int $\mathbf{J}$ Mol Sci 18:1450.

89. Oskowitz A, H McFerrin, M Gutschow, ML Carter and R Pochampally. (2011). Serum-deprived human multipotent mesenchymal stromal cells (MSCs) are highly angiogenic. Stem Cell Res 6:215-225.

90. da Silva AF, K Silva, LA Reis, VPC Teixeira and N Schor. (2015). Bone marrow-derived mesenchymal stem cells and their conditioned medium attenuate fibrosis in an irreversible model of unilateral ureteral obstruction. Cell Transplant 24:2657-2666.

91. Chen L, Y Xu, J Zhao, Z Zhang, R Yang, J Xie, X Liu and $S$ Qi. (2014). Conditioned medium from hypoxic bone marrow-derived mesenchymal stem cells enhances wound healing in mice. PLoS One 9:e96161.

92. Aryan A, M Bayat, S Bonakdar, S Taheri, N Haghparast, M Bagheri, A Piryaei and M-A Abdollahifar. (2018). Human bone marrow mesenchymal stem cell conditioned medium promotes wound healing in deep second-degree burns in male rats. Cells Tissues Organs 206:317-329.

93. Tsai M-J, D-Y Liou, Y-R Lin, C-F Weng, M-C Huang, W-C Huang, F-W Tseng and H Cheng. (2018). Attenuating spinal cord injury by conditioned medium from bone marrow mesenchymal stem cells. J Clin Med 8:23.

94. Bian S, L Zhang, L Duan, X Wang, Y Min and H Yu. (2014). Extracellular vesicles derived from human bone marrow mesenchymal stem cells promote angiogenesis in a rat myocardial infarction model. J Mol Med (Berl) 92:387-397.

95. Biancone L, S Bruno, MC Deregibus, C Tetta and G Camussi. (2012). Therapeutic potential of mesenchymal stem 
cell-derived microvesicles. Nephrol Dial Transplant 27: 3037-3042.

96. Baglio SR, DM Pegtel and N Baldini. (2012). Mesenchymal stem cell secreted vesicles provide novel opportunities in (stem) cell-free therapy. Front Physiol 3:359.

97. Paul G and SV Anisimov. (2013). The secretome of mesenchymal stem cells: potential implications for neuroregeneration. Biochimie 95:2246-2256.

98. Salgado AJ and JM Gimble. (2013). Secretome of mesenchymal stem/stromal cells in regenerative medicine. Biochimie 95:2195.

99. Teixeira FG, MM Carvalho, N Sousa and AJ Salgado. (2013). Mesenchymal stem cells secretome: a new paradigm for central nervous system regeneration? Cell Mol Life Sci 70:3871-3882.
Address correspondence to: Dr. Michael G. Fehlings Spinal Program

Toronto Western Hospital

University Health Network 399 Bathurst Street, Suite 4W-449

Toronto, ON M5T 2S8

Canada

E-mail: michael.fehlings@uhn.ca

Received for publication April 23, 2020

Accepted after revision September 22, 2020

Prepublished on Liebert Instant Online September 23, 2020 